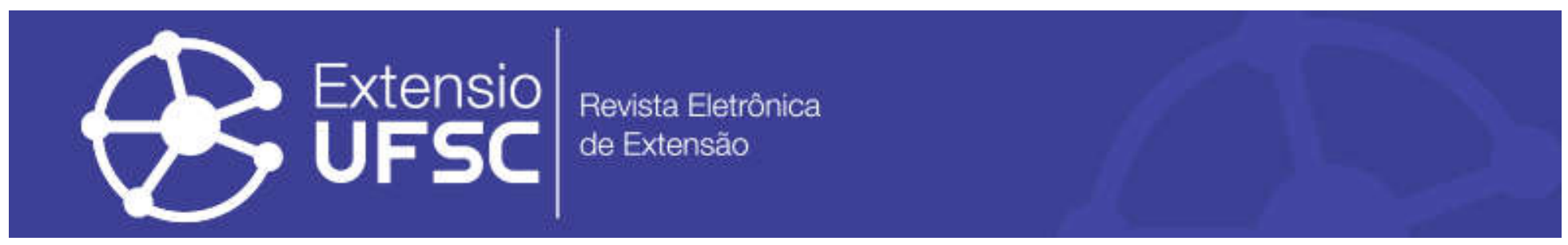

\title{
ENTRE CAFÉS, REAGENTES, MULHERES E EMPODERAMENTO: RELATO SOBRE O “GLOBAL WOMEN'S BREAKFAST” EM CURITIBA
}

\author{
Gabriela Ferreira \\ Universidade Federal do Paraná \\ gabriela.f@ufpr.br \\ Camila Silveira \\ Universidade Federal do Paraná \\ camilasilveira@ufpr.br
}

\begin{abstract}
Resumo
Em 2019, a União Internacional de Química Pura e Aplicada completou 100 anos e uma das comemorações foi o Global Women's Breakfast, com o objetivo de dar visibilidade às mulheres da Química. O presente relato descreve como ocorreu o "Café da manhã com as Químicas da UFPR". Realizado na Universidade Federal do Paraná, reuniu professoras, pesquisadoras, técnicas, alunas e demais pessoas interessadas em pautas feministas e Ciência, para conversar sobre desigualdade de gênero no campo da Química, machismo e maternidade. A iniciativa contou com a presença de mais de 150 participantes e gerou debates sobre as relações de gênero que permeiam a Química. O evento também proporcionou outras ações neste sentido, como a realização de outros eventos e projetos sobre a temática. Ao redor do mundo, a comemoração se deu em mais de 200 localidades e, devido ao seu alcance, a edição de 2021 já está sendo organizada. Palavras-chave: Desigualdade de Gênero. Mulheres na Química. IUPAC. Café da Manhã. Maternidade.
\end{abstract}

\section{AMONG COFFEES, REAGENTS, WOMEN AND EMPOWERING: REPORT ABOUT THE “GLOBAL WOMEN'S BREAKFAST” IN CURITIBA}

\begin{abstract}
In 2019 International Union of Pure and Applied Chemistry celebrated its 100th anniversary and one of the celebrations was the Global Women's Breakfast, with the objective of giving visibility to the women in Chemistry. This report describes how occured the "Breakfast with the UFPR Chemistry women". It was held at Universidade Federal do Paraná, bringing together teachers, researchers, technicians, students and other people interested in feminist guidelines and science to talk about gender inequality in Chemistry, machism and motherhood. The initiative was attended by over 150 participants and generated debates about the gender relations that permeate Chemistry. The event also provided other actions in this regard, such as the realization of other events and projects on the theme. Around the world, the celebration took place in more than 200 locations and, because of its reach, the 2021 edition is already being organized.
\end{abstract}

Keywords: Gender Inequality. Women in Chemistry. IUPAC. Breakfast. Motherhood.

\section{ENTRE CAFÉS, REACTIVOS, MUJERES Y EMPODERAMIENTO: INFORME SOBRE EL “GLOBAL WOMEN'S BREAKFAST” EN CURITIBA}

\section{Resumen}

En 2019, la Unión Internacional de Química Pura y Aplicada celebró su centenario y una de las celebraciones fue el Global Women's Breakfast, con el objetivo de dar visibilidad a las mujeres en la Quimica. Este informe describe cómo ocurrió el "Desayuno con las Quimicas de UFPR". Celebrada en la Universidad Federal de Paraná, reunió a docentes, investigadores, técnicos, estudiantes y otras personas interesadas en las pautas feministas y la ciencia, para hablar sobre la desigualdad de género en Quimica, machismo y maternidad. A la iniciativa asistieron más de 150 participantes y generó debates sobre las relaciones de género que impregnan la Quimica. El evento también proporcionó otras acciones en este sentido, como la celebración de otros eventos y proyectos sobre el tema. En todo el mundo, la celebración se llevó a cabo en más de 200 lugares y, debido a su alcance, la edición 2021 ya se está organizando.

Palavras clave: Desigualdad de Género. Mujeres en Quimica. IUPAC. Desayuno. Maternidad. 
Entre cafés, reagentes, mulheres e empoderamento: relato sobre o "Global Women's Breakfast" em Curitiba

\section{INTRODUÇÃO}

As relações de gênero são constituídas sob uma lógica binária e hierárquica, na qual diferentes características são atribuídas a mulheres e homens. Associado a isso, o preconceito que subalterniza as mulheres age, dentre outras estratégias, por meio da divisão sexual do trabalho, que determina quais profissões são adequadas a cada um dos gêneros e, de acordo com Helena Hirata ${ }^{1}$ e Danièle Kergoat (2007), carreiras de maior valor social são culturalmente masculinas.

Considerando que a Universidade reúne, de certa forma, uma elite intelectual, a mesma é um ambiente prestigioso e, portanto, visto como masculino. Contudo, no campo das Ciências Exatas a situação se agrava, pois, nele, as características masculinas são ainda mais valorizadas, tornando-o supostamente inadequado às mulheres. De acordo com Betina Stefanello Lima (2013), não existem impedimentos formais para as mulheres seguirem a carreira científica, mas ocorre o fenômeno denominado "labirinto de cristal", que representa as dificuldades, violências e preconceitos com os quais as mulheres se deparam ao longo de suas trajetórias acadêmicas.

O termo "cristal" é proposto por Lima (2013) para demonstrar que os obstáculos são invisíveis no contexto das Ciências Exatas, passando despercebidos devido à naturalização do preconceito de gênero. Neste sentido, Fabiane Ferreira Silva e Paula Regina Costa Ribeiro reforçam a importância de se atentar ao machismo velado, afirmando que o preconceito de gênero, "que institui e determina constantemente uma imagem negativa e inferiorizada das mulheres, nem sempre se dá de forma explícita; muitas vezes, ele se dá de forma velada, sutil, e aí residem, justamente, sua força e eficácia” (SILVA; RIBEIRO, 2014, p. 455).

Assim, as mulheres que seguem a trajetória científica estão em um espaço que, culturalmente, não lhes pertence, resultando em obstáculos que as afastam das Ciências Exatas ou dificultam sua ascensão e permanência. Para Léa Velho (2006), isso também pode ser entendido devido às carreiras científicas serem construídas sob um "modelo masculino de carreira", que é hostil ao feminino. Um dos principais problemas deste "modelo" é a desconsideração de demandas especialmente femininas, como a maternidade. A Lei 13.536, que determina o direito ao afastamento por maternidade ou adoção durante a Pós-Graduação, foi sancionada somente em 15 de dezembro de 2017 (BRASIL, 2017). Anterior a isso, pós-graduandas que se tornassem mães eram obrigadas a lidar sozinhas com a situação, muitas vezes desistindo da Pós-Graduação.

Laura Davis Mattar e Carmen Simone Grilo Diniz (2012) afirmam que a maternidade é vista como algo naturalmente feminino, uma das principais funções das mulheres na sociedade.

\footnotetext{
${ }^{1}$ Os prenomes das autoras referenciadas foram apresentados nas primeiras vezes em que cada uma foi citada, de
} modo a possibilitar que os gêneros sejam reconhecidos e, assim, dar visibilidade às mulheres. 
Entre cafés, reagentes, mulheres e empoderamento: relato sobre o "Global Women's Breakfast" em Curitiba

Em contrapartida, do ponto de vista feminista, a maternidade se trata de uma imposição e não de uma escolha autônoma das mulheres, na maioria dos casos. Elas são pressionadas a serem mães devido a uma obrigação social colocada por instituições dominadas por homens, sob pena de serem estigmatizadas caso não o façam. Baseando-se na biologia dos corpos, a maternidade é uma identidade forçada e, associado a isso, existe também a atribuição dos cuidados com as(os) filhas(os) somente à figura materna. De acordo com Raísa Pinheiro Arruda (2018, p. 17), há uma "crença social de que a mãe é a única pessoa apta a cuidar integralmente de um bebê e uma criança pequena, enquanto o pai é relegado à função de provedor e protetor". Sendo assim, a mãe se torna a principal responsável por esses cuidados, que aumentam significativamente suas demandas de trabalho, e acabam restringindo-a ao espaço privado e trazendo impacto à sua carreira. Consequentemente, as potencialidades femininas tornam-se limitadas, acentuando a desigualdade de gênero (MATTAR; DINIZ, 2012).

Apesar disso, Arruda (2018) observa que a parentalidade tem passado por mudanças, contando mais com a presença masculina nos últimos anos. Um importante avanço foi trazido pela Lei 13.257, de 8 de março de 2016, na qual fica instituída a possibilidade de a licençapaternidade ter a duração de 20 dias, não mais apenas de cinco dias (BRASIL, 2016). Essa Lei representa uma conquista, no sentido de reforçar que o cuidado com as crianças é responsabilidade da mãe e do pai conjuntamente, contudo, reconhecemos que a licençapaternidade precisa avançar, por ainda contar com um curto período.

Entretanto, o papel do pai continua sendo secundário, ocupando uma posição de "ajudante" no processo da criação e do cuidado e, além disso, "apesar de todos os avanços e transformações sociais vividos da década de 1970 até os tempos atuais, as mulheres ainda são e se sentem cobradas em ocupar este lugar” (ARRUDA, 2018, p. 57) de principais responsáveis pelos bebês e crianças, incluindo as cientistas.

De acordo com Mary Ann Mason e Marc Goulden (2002), muitas pesquisadoras encaram a maternidade como algo prejudicial às suas carreiras, devido às dificuldades de conciliação. $O$ trabalho massivo na academia, incluindo longas cargas horárias, viagens e a comum necessidade de mudar de localidade para assumir cargos, afasta as mulheres que são mães e as obriga a deixar a profissão. Para as pesquisadoras, "existe a questão adicional que docentes devem ir aonde os empregos estão e mulheres com famílias não possuem essa flexibilidade. [...] essas mulheres, na maioria das vezes, não chegam tão longe [...]; elas optam por um caminho diferente antes" (MASON; GOULDEN, 2002, p. 6, tradução nossa).

Reconhecemos que a realidade estadunidense apresentada no trabalho de Mason e Goulden (2002) é diferente da brasileira, em especial, tratando-se da divisão sexual do trabalho. 
Entre cafés, reagentes, mulheres e empoderamento: relato sobre o "Global Women's Breakfast" em Curitiba

Para discutir sobre o tema adequadamente, precisaríamos nos atentar ao contexto econômico, social e político de cada realidade, sem deixar de lado também as questões étnico-raciais, o que não foi realizado no presente trabalho. A divisão sexual do trabalho ocorre de diferentes formas no Brasil e nos Estados Unidos, mas existem alguns aspectos que são comuns a ambos, como as dificuldades enfrentadas por pesquisadoras mães ao longo da carreira. Estela M. L. Aquino demonstra isso ao afirmar que, para as cientistas brasileiras, "quando os filhos chegam, as mulheres em carreira científicas são obrigadas a fazer escolhas difíceis, como o adiamento da ocupação de cargos e uma menor disponibilidade para viagens" (AQUINO, 2006, p. 17).

Dessa forma, existem diversos obstáculos com relação à maternidade que precisam ser discutidos. Questões relacionadas à queda da produtividade após a maternidade e a falta de incentivos para mães cientistas, além das dificuldades com as quais elas se deparam, como a diminuição na mobilidade geográfica, o sentimento de culpa por não se dedicarem como desejam à família e à carreira, as múltiplas tarefas que precisam desempenhar, entre diversas outras. Considerando a desigualdade de gênero nas Ciências Exatas e a importância de dar visibilidade às trajetórias de mulheres cientistas, em especial as que também são mães, e às pautas das mulheres em geral, é necessário proporcionar momentos para reflexões e para a promoção da sororidade e da busca pela equidade.

\section{Um dia dedicado às mulheres e meninas cientistas}

A busca pela equidade de gênero é uma das mais importantes pautas da luta feminista e se estende também para o campo acadêmico. No contexto das Ciências Exatas, e da Química em particular, Vanderlan Bolzani (2017) afirma que a presença das mulheres costuma ser lembrada e inspirada pela célebre Marie Curie, mas em mais de 100 anos do Prêmio Nobel de Química, apenas sete mulheres foram laureadas (THE NOBEL PRIZE, c2021).

De acordo com o site da Organização das Nações Unidas para a Educação, a Ciência e a Cultura (UNESCO, c2017a), menos de 30\% de cientistas ao redor do mundo são mulheres. Ainda, para alcançar os objetivos da "Agenda 2030 para o Desenvolvimento Sustentável”, serão necessários todos os esforços de mulheres e homens no campo científico, demonstrando a urgência em combater o androcentrismo para que não se percam os talentos femininos.

Neste contexto, foi aprovada em 22 de dezembro de 2015 a criação do Dia Internacional das Mulheres e Meninas na Ciência. A comemoração se dá anualmente em 11 de fevereiro e é uma iniciativa da UNESCO e da Organização das Nações Unidas (ONU) Mulheres. Conforme a UNESCO (c2017a), a celebração tem como objetivo "promover o acesso integral e igualitário da 
Entre cafés, reagentes, mulheres e empoderamento: relato sobre o "Global Women's Breakfast" em Curitiba

participação de mulheres e meninas na ciência", além de afirmar que a data é um lembrete da importância que meninas e mulheres possuem para o desenvolvimento científico, reiterando a necessidade de incentivá-las e empoderá-las enquanto cientistas.

As mulheres da Química, de acordo com Marcy H. Towns, contaram também com uma iniciativa da União Internacional de Química Pura e Aplicada (IUPAC, sigla em inglês) em 2019, em consonância com o Dia Internacional das Mulheres e Meninas na Ciência. Celebrando seu centésimo aniversário, a IUPAC realizou uma série de eventos comemorativos e um deles esteve especialmente relacionado à pauta das mulheres cientistas da Química (TOWNS, 2019).

Em 12 de fevereiro de 2019, a IUPAC propôs o evento “IUPAC100 Global Women's Breakfast - Empowering Women in Chemistry: A Global Networking Event" ("IUPAC100 Café da Manhã Global das Mulheres - Empoderando as Mulheres da Química: Um Evento Global”, tradução nossa). O objetivo foi dar visibilidade às mulheres químicas ao redor do mundo e encorajá-las a divulgarem suas pesquisas e trabalhos, compartilhar experiências, conhecer novas pesquisadoras, trocar vivências e explorar oportunidades. Além disso, a IUPAC também incentivou que as mulheres envolvidas no evento divulgassem as ações por meio de sites, pôsteres e o uso das hashtags \#GlobalBreakfast e \#IUPAC100 nas redes sociais (IUPAC, c2020).

O evento ocorreu em 204 localidades diferentes, incluindo mais de 50 países, como mostra o mapa disponibilizado no site oficial, demonstrado na Ilustração 1.

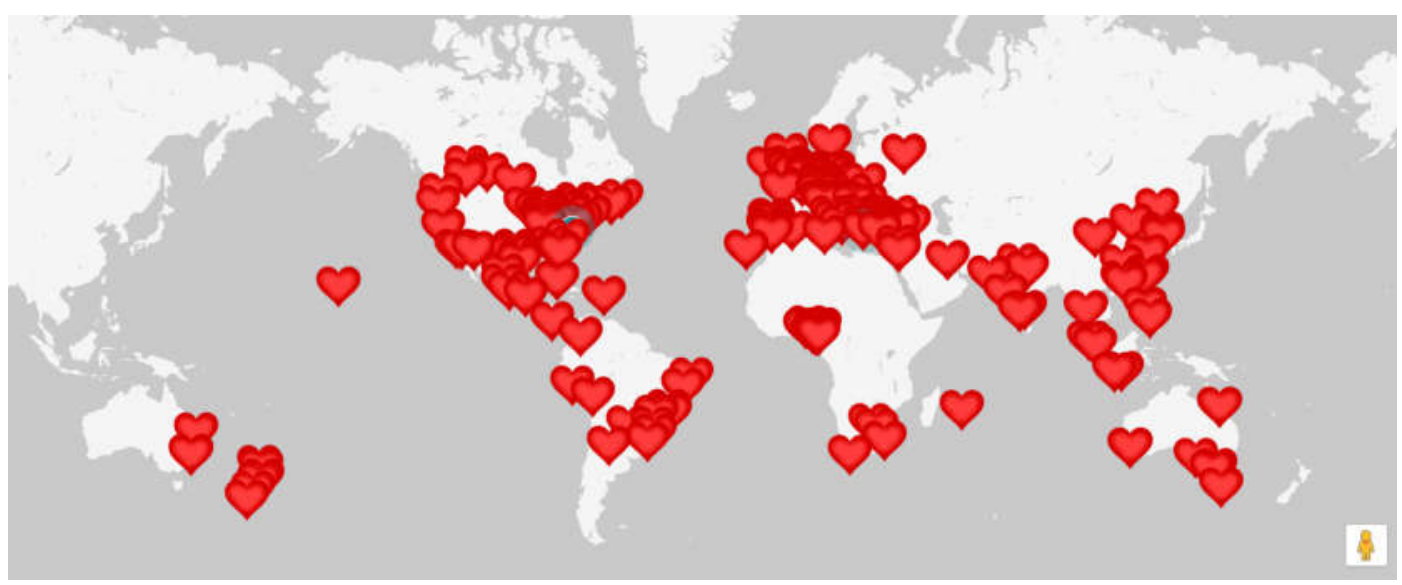

Ilustração 1 - Localidades onde ocorreram comemorações do "IUPAC100 Global Women's Breakfast". Fonte: IUPAC, c2020 (modificado).

No Brasil, foram realizadas comemorações em nove localidades nos Estados de Minas Gerais, Paraná, Santa Catarina, Alagoas, Rio Grande do Sul, Bahia e São Paulo.

Em Curitiba, a comemoração ocorreu no campus Centro Politécnico da Universidade Federal do Paraná (UFPR), no Departamento de Química (DQUI). O evento, de natureza 
Entre cafés, reagentes, mulheres e empoderamento: relato sobre o "Global Women's Breakfast" em Curitiba

extensionista, foi pensado na forma de uma roda de conversa em meio a um café da manhã, acolhendo participantes das comunidades interna e externa e, além disso, sendo destinado a mulheres químicas, bem como de outras áreas, e a todas(os) as(os) interessadas(os) em Ciências, maternidade e feminismo. Com relação à comunidade externa à Universidade, a iniciativa teve como intuito possibilitar que essas pessoas tivessem contato com a realidade e as dificuldades das mulheres cientistas, favorecendo a troca de experiências e incentivando a desconstrução de estereótipos relacionados à maternidade nas Ciências. O evento foi dedicado especialmente às mães cientistas, considerando que a maternidade nas Ciências necessita de debates e reflexões, visando o empoderamento das mães pesquisadoras e a busca por iniciativas de apoio a esta pauta.

Mulheres nas Ciências Exatas sofrem um grande preconceito de gênero, mas as mães ainda se deparam com mais discriminações. Portanto, a escolha do tema justifica-se na necessidade de tratar sobre o assunto, com o intuito de proporcionar iniciativas de apoio às mães cientistas e respeito. Assim, o presente artigo é um relato de experiência sobre o "Café da Manhã com as Químicas da UFPR: o (im)provável empoderamento feminino", ocorrido em 12 de fevereiro de 2019, na cidade de Curitiba/PR, estando associado ao evento global da IUPAC para dar visibilidade às mulheres químicas e suas demandas.

\section{METODOLOGIA}

\section{A iniciativa das gurias químicas de Curitiba}

O "Café da manhã com as Químicas da UFPR: o (im)provável empoderamento feminino" foi idealizado e coordenado pela Prof. ${ }^{a}$ Dr. ${ }^{a}$ Camila Silveira (Departamento de Química da Universidade Federal do Paraná), juntamente com a Prof. ${ }^{a}$ Dr. ${ }^{a}$ Elisa Orth (Departamento de Química da Universidade Federal do Paraná) e a Prof. ${ }^{a}$ Dr. ${ }^{a}$ Juliana Paula da Silva (Departamento de Química da Universidade Federal de Santa Catarina). Além de contar com uma equipe de apoio composta por alunas da Pós-Graduação, Leice Milla Ribeiro, e da Graduação, Gabriela Ferreira e Iohanna Prado.

O evento foi divulgado em uma página do Facebook ${ }^{2}$, criada especialmente para este propósito, e aberta às comunidades acadêmica e externa. O “Café da manhã com as Químicas da UFPR” iniciou às 9h do dia 12 de fevereiro de 2019, um dia após a comemoração do Dia Internacional de Mulheres e Meninas na Ciência. Ocorreu em uma sala do Departamento de Química da UFPR, em Curitiba, onde foi oferecido o café da manhã, em um ambiente decorado

\footnotetext{
${ }^{2}$ Disponível em: https://www.facebook.com/events/607245043049018/. Acesso em: 8 jan. 2021.
} 
Entre cafés, reagentes, mulheres e empoderamento: relato sobre o "Global Women's Breakfast" em Curitiba

com flores e uma tabela periódica colorida, lembrando a comemoração dos 150 anos da Tabela Periódica, ocorrida também em 2019 (UNESCO, c2017b). Em relação ao espaço físico, as cadeiras foram dispostas em semicírculo na sala, com o intuito de proporcionar que as(os) participantes se olhassem e que não houvesse demonstração de hierarquia no espaço físico.

A programação do café da manhã curitibano incluiu uma roda de conversa, iniciada pela Prof. ${ }^{a}$ Dr. ${ }^{a}$ Camila Silveira e pela Prof. ${ }^{a}$ Elisa Orth seguida de debate; uma mesa redonda sobre maternidade mediada pela Prof. ${ }^{a}$ Dr. ${ }^{a}$ Camila Silveira; e a projeção do documentário "Fator F" (FATOR F, 2018). O principal tema abordado foi a maternidade nas Ciências, uma questão de grande relevância para as mulheres pesquisadoras.

Além disso, a exposição "Mais (cons)Ciência, Menos Desigualdade de Gênero", elaborada no contexto da Semana Nacional de Ciência e Tecnologia (SNCT) 2018, fez parte da iniciativa, e foi montada no saguão de entrada do Departamento de Química, local de grande circulação de pessoas, como uma ação para reforçar a necessidade de se debater as questões de gênero naquele espaço. A exposição trazia informações sobre as mulheres ganhadoras do Prêmio Nobel de várias áreas, notícias sobre estudos de mulheres cientistas, fotografias de pesquisadoras de diversos campos de atuação e um totem de Bertha Lutz, bióloga e ativista feminista que foi uma das responsáveis pelo voto feminino no Brasil.

\section{RESULTADOS E DISCUSSÃO}

\section{Café da manhã com as Químicas da UFPR: narrativas de luta e resistência}

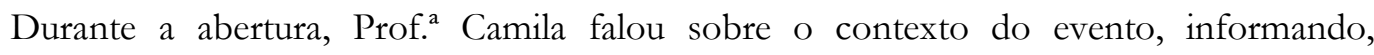
inclusive, quais as demais localidades brasileiras onde o mesmo estaria ocorrendo quase simultaneamente. Na sequência, passou a palavra à Prof. ${ }^{a}$ Elisa, que trouxe informações sobre a situação das mulheres nas Ciências, demonstrando dados sobre as bolsas concedidas pelo Conselho Nacional de Desenvolvimento Científico e Tecnológico $(\mathrm{CNPq})$ às pesquisadoras e pesquisadores de destaque, fazendo correlações entre hierarquia, prestígio e gênero. A fala de Elisa, intitulada "Onde estão as cientistas no Brasil?", foi recebida com olhares surpresos por parte do público, majoritariamente feminino. Ela enfatizou sobre como a desigualdade entre bolsas recebidas por mulheres e homens aumenta conforme se sobe na hierarquia acadêmica.

De acordo com Lima (2013), as pesquisadoras vivenciam dois tipos de exclusão nas Ciências Exatas: a exclusão horizontal, que diz respeito às mulheres serem minoria neste campo; e a exclusão vertical, que demonstra como as mulheres não atingem os níveis mais altos da 
Entre cafés, reagentes, mulheres e empoderamento: relato sobre o "Global Women's Breakfast" em Curitiba

carreira acadêmica. Os dados apresentados por Elisa demonstraram as duas exclusões, mas, principalmente, a exclusão vertical. De acordo com Hirata e Kergoat (2007), o trabalho doméstico é constituído como função natural e exclusiva feminina e, apesar da luta feminista e a chegada das mulheres brancas ao mercado de trabalho, elas não se tornaram isentas de sua função intrínseca de "dona de casa", culminando em um acúmulo de trabalho. A carreira científica, por sua vez, demanda muito esforço e dedicação, o que traz ainda mais dificuldade para as pesquisadoras, pois, com as responsabilidades familiares e domésticas, a demanda de trabalho se torna massiva e dificulta que elas consigam manter o ritmo que desejam nas Ciências. Existem exceções de mulheres que chegaram ao topo da carreira acadêmica, mas, geralmente, isto está associado à renúncia de funções supostamente femininas (LIMA, 2013).

Em seguida, Prof. ${ }^{a}$ Camila retornou com a fala "As mulheres cientistas na Química da UFPR", trazendo uma exposição sobre a situação do Departamento de Química da UFPR quanto à desigualdade de gênero. Sendo pesquisadora da área de Mulheres nas Ciências Exatas, Camila trouxe dados alarmantes de estudos recentes de seu grupo de pesquisa, que demonstraram a sub-representação feminina entre docentes em praticamente todas as áreas da Química. A Tabela 1 traz os dados abordados na fala, referentes ao ano de 2018, sendo que F representa "Feminino" e M "Masculino".

\begin{tabular}{c|c|c|c|c|c|c|c|c|c}
\hline \multicolumn{2}{c|}{ Ensino de Química } & \multicolumn{2}{|c|}{ Físico-Química } & \multicolumn{2}{c|}{ Química Analítica } & \multicolumn{2}{c}{ Química Inorgânica } & \multicolumn{2}{c}{ Química Orgânica } \\
\hline $\mathrm{F}$ & $\mathrm{M}$ & $\mathrm{F}$ & $\mathrm{M}$ & $\mathrm{F}$ & $\mathrm{M}$ & $\mathrm{F}$ & $\mathrm{M}$ & $\mathrm{F}$ & $\mathrm{M}$ \\
\hline $3(75 \%)$ & 1 & $5(50 \%)$ & 5 & $4(29 \%)$ & 10 & $4(33 \%)$ & 8 & $6(35 \%)$ & 11 \\
\hline
\end{tabular}

Tabela 2 - Relação de docentes do Departamento de Química da UFPR por gênero e área. Fonte: Autoras, 2019.

Camila também fez correlações entre os números na Graduação e na Pós-Graduação, pontuando a ruptura que há, pois, as mulheres são maioria entre as graduadas e pós-graduadas, mas não atingem o cargo docente. Esses dados estão na Tabela 2, em que temos a quantidade de egressas(os) na Graduação em 2018 e na Pós-Graduação no período de 2012 a 2017.

\begin{tabular}{c|c|c|c|c|c}
\hline \multicolumn{2}{c|}{$\begin{array}{c}\text { Graduação } \\
2018\end{array}$} & \multicolumn{2}{c|}{$\begin{array}{c}\text { Mestrado } \\
2012-2017\end{array}$} & \multicolumn{2}{c}{$\begin{array}{c}\text { Doutorado } \\
2012-2017\end{array}$} \\
\hline $\mathrm{F}$ & $\mathrm{M}$ & $\mathrm{F}$ & $\mathrm{M}$ & $\mathrm{F}$ & $\mathrm{M}$ \\
\hline $20(71 \%)$ & 8 & $88(63 \%)$ & 51 & $51(53 \%)$ & 46 \\
\hline
\end{tabular}

Tabela 2 - Relação de egressas e egressos na Graduação e Pós-Graduação em Química da UFPR. Fonte: Autoras, 2019.

Novamente a pauta da exclusão vertical feminina se faz presente, uma vez que o cargo docente em uma Universidade pode ser considerado como uma posição de prestígio nas Ciências. 
Entre cafés, reagentes, mulheres e empoderamento: relato sobre o "Global Women's Breakfast" em Curitiba

Apesar de a docência ser culturalmente feminizada, o seu patamar mais alto, o Ensino Superior, é um espaço majoritariamente masculino, segundo Cláudia Pereira Vianna (2001/02). Dessa forma, compreendemos o motivo de as mulheres serem mais representativas na área de Ensino de Química, mas em números absolutos, elas continuam sendo poucas. Nas Ciências Exatas a situação agrava, pois, mulheres são colocadas como inadequadas a carreiras que exijam maior racionalidade e lógica. Isso explica, de certa forma, a sub-representação feminina no corpo docente da área da Química na UFPR, como demonstrado pela Prof. ${ }^{a}$ Dr. ${ }^{a}$ Camila, no qual as mulheres representam aproximadamente $38 \%$ do total.

Com isso, Camila fez questionamentos e provocações ao público, abrindo o debate. $\mathrm{Na}$ conversa, foram trazidos relatos de mulheres e homens afirmando nunca terem se dado conta da desigualdade que as(os) cerca, levantando-se questões e possíveis explicações para o fenômeno. Esta constatação é explicada por Silva e Ribeiro (2014), ao afirmarem que nas Ciências Exatas o preconceito é implícito e reside nas pequenas atitudes cotidianas. Os obstáculos aos quais as mulheres se deparam podem ser de difícil percepção (LIMA, 2013).

Além disso, de acordo com as(os) participantes, a Química, enquanto Ciência Exata, é tida como uma carreira masculina, pois necessita de raciocínio lógico e envolve muitos cálculos, o que afasta as mulheres. Também foi abordada a múltipla jornada de trabalho feminina e como ela influencia negativamente nas profissões das mulheres, quaisquer que sejam, mas especialmente na carreira científica, que exige grande dedicação. Estas constatações vão de acordo com Lima (2013) e Hirata e Kergoat (2007) que discorrem sobre a naturalização do trabalho doméstico enquanto feminino e como isto prejudica a carreira acadêmica. Além de demonstrarem como a Química se encontra no "modelo masculino de carreira" (VELHO, 2006).

Em seguida, foi iniciada a mesa redonda, intitulada "Maternidade e Ciência: ações, experiências e reflexões". Neste momento, houve falas de mulheres atuantes no Departamento de Química da UFPR, seja como docentes, pesquisadoras, técnicas ou alunas. Foram relatadas experiências sobre maternidade e as dificuldades que a permeiam. As participantes abordaram o preconceito vivenciado enquanto mães, as faltas de incentivos institucionais, as dificuldades em conciliar as múltiplas tarefas dentro e fora de casa, dentre diversas outras questões que mães cientistas comumente precisam lidar, e que vão ao encontro do que Arruda (2018) discorre em sua pesquisa. Mas também foram trazidos relatos sobre apoios recebidos por colegas, orientadoras(os) e companheiras(os), que foram de grande importância para que permanecessem na carreira. Apesar do aumento da participação masculina na criação das(os) filhas(os) e da Lei que aumenta a licença-paternidade, a contribuição do pai no cuidado com as crianças, por vezes, ainda se dá sob o regime de ajuda e não como divisão igualitária de tarefas. Ou seja, a mãe 
Entre cafés, reagentes, mulheres e empoderamento: relato sobre o "Global Women's Breakfast" em Curitiba

permanece como principal responsável e, consequentemente, tem um maior impacto em sua vida profissional do que o pai (ARRUDA, 2018; MATTAR; DINIZ, 2012).

Existem conflitos entre "ser cientista" e "ser mulher", fazendo com que mulheres, muitas vezes, tenham que escolher entre os dois caminhos (LIMA, 2013) e aqui entra, por exemplo, a tomada de decisão entre ser mãe ou se dedicar inteiramente à Química. A opção por ambos ocasiona uma série de dificuldades e "a mulher que decide seguir uma carreira científica poderá pensar duas vezes em escolher ser mãe ou ser cientista, em função da necessidade de conciliar a carreira com a maternidade" (SILVA; RIBEIRO, 2014, p. 463).

A maternidade, então, torna-se uma escolha difícil por representar a diminuição na produtividade, as lacunas na pesquisa e na produção, o aumento da demanda de trabalho, entre outros fatores que prejudicam a vida profissional das pesquisadoras. Ao mesmo tempo, a sociedade impõe que as mulheres sejam mães (MATTAR; DINIZ, 2012). Dessa maneira, as cientistas se encontram em um impasse: ser mãe cientista é um grande desafio, que culmina, inclusive, em preconceitos dentro da academia; mas não ser mãe resulta em ser estigmatizada socialmente, por não cumprir uma função supostamente natural. Estas questões foram levantadas pelas participantes da roda de conversa, relatando as dificuldades e sacrifícios vivenciados, trazendo também as discriminações no ambiente de trabalho por serem mães.

Com relação a isso, Arruda (2018) trata em seu estudo sobre os impactos e as percepções de mulheres cientistas na Pós-Graduação. A autora faz correlações entre a construção social da maternidade e a ocupação das mulheres no mercado de trabalho, demonstrando como a culpa se faz presente na vida de pesquisadoras que são mães. Ao longo da conversa, a culpa também surgiu nos relatos por diversas vezes, acompanhada pela cobrança imposta às mulheres que abdicam de suas profissões em função da família e vice-versa.

Na sequência, com a exibição do documentário "Fator F" (FATOR F, 2018), pôde-se perceber como as dificuldades associadas à maternidade são comuns dentre mulheres cientistas de diferentes áreas, de modo mais abrangente. Os relatos apresentados no vídeo causaram comoção entre todas(os), que demonstravam se identificarem com as narrativas retratadas.

O documentário em questão apresenta um panorama sobre os problemas enfrentados por mulheres que optam pelas Ciências e pela maternidade. Traz relatos de mães cientistas e dados constituídos pelo Parent in Science (c2018) sobre os impactos da maternidade na carreira acadêmica, principalmente com relação à produtividade, além de falar sobre a pesquisa liderada pela Prof. ${ }^{a}$ Dr. ${ }^{a}$ Fernanda Staniscuaski, também denominada "Fator F", que busca formas de apoiar e incentivar mães cientistas. De acordo com o documentário, um dos principais fatores que culminam em tantas dificuldades é a divisão desigual das tarefas familiares e domésticas. Isso 
Entre cafés, reagentes, mulheres e empoderamento: relato sobre o "Global Women's Breakfast" em Curitiba

também é apontado por Hirata e Kergoat (2007), ao demonstrarem como o trabalho doméstico é construído como exclusivamente feminino, e por Arruda (2018) e Mattar e Diniz (2012), ao afirmarem que as mulheres ainda são as principais responsáveis pelas(os) filhas(os).

No documentário, assim como nos relatos do público, a questão da mobilidade geográfica foi levantada. Mason e Goulden (2002) afirmam que professoras(es) universitárias(os) muitas vezes precisam mudar de localidade para exercer a profissão. Quando se trata das mães, tais mudanças requerem maiores esforços e obstáculos, eventualmente impedindo que mães cientistas atinjam determinados cargos. Para além disso, a participação em congressos e outros eventos e a realização de intercâmbios também se tornam comprometidas com a chegada da maternidade.

Muitas participantes se sentiram encorajadas a dividir suas histórias, estando acolhidas em um momento de empatia e sororidade. Angústias, dores, conquistas e indignações foram compartilhadas por mulheres de diferentes trajetórias, contextos e em momentos distintos da carreira, ao passo que as demais demonstravam se identificar e se solidarizar.

Ao final, houve a declamação de uma poesia autoral por parte de uma professora que estava no público, tratando sobre maternidade nas Ciências, o que causou grande emoção às(aos) presentes, que aplaudiram por vários minutos. Por fim, uma das conclusões que uma participante chegou foi que iniciativas como aquela eram imprescindíveis e que, somente unidas, as mulheres poderiam vencer o preconceito de gênero. Todas(os) aparentaram concordar com a colocação.

No site do evento global (IUPAC, c2020) estão publicados fotos, vídeos e flyers do mundo todo sobre esta iniciativa, incluindo fotos do café da manhã na UFPR. Ainda, a Ilustração 2 mostra a decoração do evento curitibano e a Prof. ${ }^{a}$ Dr. ${ }^{a}$ Camila Silveira durante sua fala inicial..

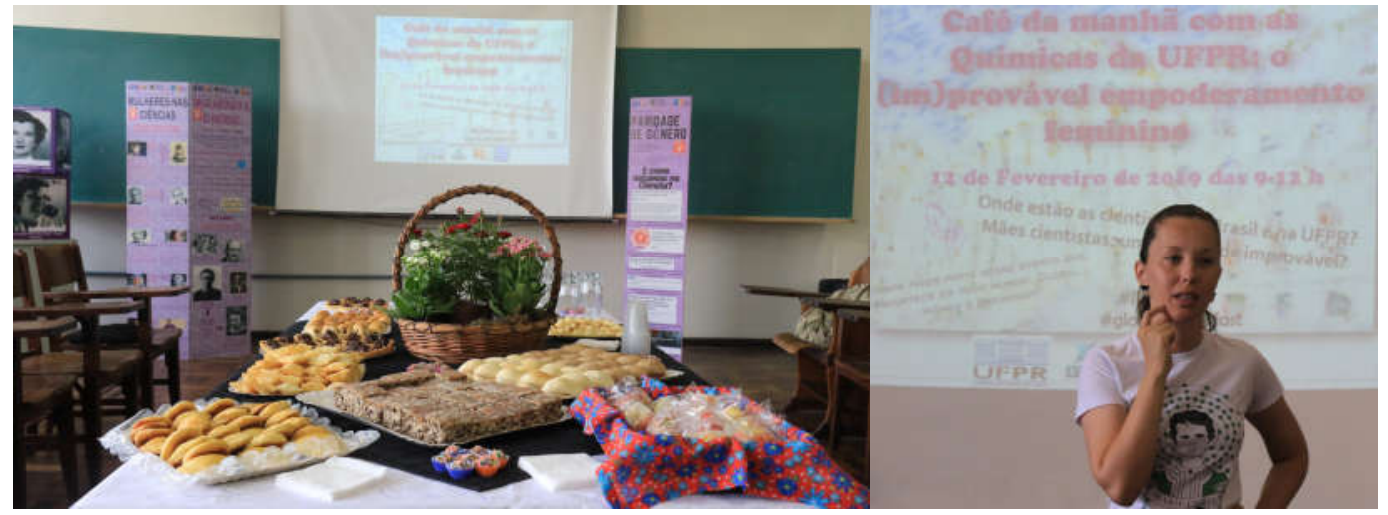

Ilustração 2 - (a) Decoração do "Café da Manhã com as Químicas da UFPR”, à esquerda; e (b) Prof. ${ }^{a}$ Dr. ${ }^{a}$ Camila Silveira durante sua fala inicial no "Café da Manhã com as Químicas da UFPR", à direita. Fonte: Autoras, 2019. 
Entre cafés, reagentes, mulheres e empoderamento: relato sobre o "Global Women's Breakfast" em Curitiba

Contando com aproximadamente 150 participantes, de acordo com a contagem da equipe organizadora, o evento proporcionou diversas outras iniciativas que trouxeram visibilidade às pautas feministas nas Ciências Exatas na UFPR. Dentre os impactos do Café da Manhã, está a realização de um segundo evento, intitulado "I Encontro das Mulheres nas Ciências Exatas", ainda no primeiro semestre de 2019, que teve como objetivo dar visibilidade às trajetórias de mulheres nas Exatas e realizar discussões sobre a ocupação e representação femininas neste espaço. Foi realizada uma roda de conversa sobre as perspectivas futuras das mulheres cientistas, mediada pela Prof. ${ }^{a}$ Dr. ${ }^{a}$ Camila Silveira, durante a XXIV Semana Acadêmica de Química da UFPR, no segundo semestre de 2019. Também, ocorreu a segunda edição do "Café da manhã com as Químicas da UFPR”, realizado em 11 de fevereiro de 2020.

Ademais, as organizadoras foram convidadas para compor mesas redondas, dar entrevistas, realizar palestras, ministrar oficinas, entre outras atividades, para tratar sobre a temática de gênero no contexto das Ciências Exatas. Além da manutenção de projetos de pesquisa e extensão que tratam sobre o assunto, orientados pela Prof. ${ }^{a}$ Dr. ${ }^{a}$ Camila Silveira, incluindo estudantes de Doutorado, Mestrado e Iniciação Científica, que investigam sobre gênero e Ciências em diversos contextos. Um exemplo é o Projeto de Extensão "Meninas e Mulheres nas Ciências", que conta com muitos produtos e um alcance significativo.

\section{CONSIDERAÇÕES FINAIS}

A divisão sexual do trabalho (HIRATA; KERGOAT, 2007), a face sutil do preconceito no ambiente acadêmico (SILVA; RIBEIRO, 2014), os obstáculos enfrentados por mulheres cientistas (LIMA, 2013), em especial as mães cientistas (AQUINO, 2006; ARRUDA, 2018; MASON; GOULDEN, 2002; MATTAR; DINIZ, 2012), foram questões presentes ao longo de todas as conversas no evento. As narrativas das(os) participantes demonstravam, por diversas vezes, ir ao encontro das proposições das autoras, o que pode representar como tais problemáticas permeiam as relações de trabalho no geral, mas, principalmente, no campo científico. Além de alertar para a urgente necessidade de superá-las.

Ao longo do evento, percebeu-se que cada vez mais as pessoas demonstravam interesse em se expressar, o que mostra como esta pauta é presente na vida das mulheres e, além disso, como traz uma urgência em ser discutida no campo da Química. O preconceito de gênero está presente nas experiências das mulheres da Química na UFPR e elas desejam vencê-lo, elencando em suas falas também a importância da sororidade na luta pela equidade. 
Entre cafés, reagentes, mulheres e empoderamento: relato sobre o "Global Women's Breakfast" em Curitiba

O principal ponto positivo da edição do evento em Curitiba foi a visibilidade trazida às narrativas das mulheres que fazem parte do Departamento de Química na UFPR, bem como a sororidade entre as participantes ao se identificarem com histórias alheias e se perceberem acolhidas em seu local de trabalho. A tomada de consciência com relação à desigualdade de gênero tanto no contexto da UFPR, quanto de modo geral, também é uma questão positiva a ser elencada. Entretanto, um ponto a ser melhorado diz respeito à periodicidade da ação. A iniciativa da IUPAC tem como objetivo ser realizada uma vez por ano, porém, este tema precisa ser debatido ao longo de todo o ano, com vistas a se buscar ações que promovam a equidade.

Outras iniciativas emergiram após este evento no contexto da UFPR e mundialmente, tendo acontecido a segunda edição do Global Women's Breakfast 2020 e, em breve, ocorrerá a edição de 2021, que já está sendo divulgada pela IUPAC (c2021).

Por fim, o caminho para superar o machismo necessita de união, empatia e sororidade, em especial na Ciência, que muitas vezes se mostra como um espaço opressor para as mulheres. Dessa maneira, iniciativas como esta, com alcance mundial, são determinantes para que as pautas feministas tenham a visibilidade necessária e que as histórias das mulheres sejam ouvidas, reconhecidas e perpetuadas. Em especial as cientistas, que há tanto são apagadas da História. O Global Women's Breakfast em Curitiba proporcionou um momento de fortalecimento e empoderamento, levantou uma demanda para que existam mais ações como esta e trouxe motivação e fortalecimento às mulheres químicas, na busca pela equidade de gênero.

\section{AGRADECIMENTO}

Agradecemos à Fundação Araucária de Apoio ao Desenvolvimento Científico e Tecnológico do Estado do Paraná pela Bolsa concedida.

\section{REFERÊNCIAS}

2019 - Ano Internacional da Tabela Periódica dos Elementos Químicos. Organização das Nações Unidas para a Educação, a Ciência e a Cultura, c2017b. Disponível em: http://www.unesco.org/new/pt/brasilia/about-this-office/prizes-and-celebrations/2019international-year-of-the-periodic-table-of-chemical-elements/. Acesso em: 10 jan. 2020.

AQUINO, Estela M. L. Gênero e ciência no Brasil: contribuições para pensar a ação política na busca da equidade. In: Encontro Nacional Pensando Gênero e Ciência Núcleos e Grupos de Pesquisa, 2005, 2006, Brasília. Anais eletrônicos [...] Brasília: Secretaria Especial de Políticas para as Mulheres, 2006. 
Entre cafés, reagentes, mulheres e empoderamento: relato sobre o "Global Women's Breakfast" em Curitiba

ARRUDA, Raísa Pinheiro. Equilibrando os pratos: a percepção de mães docentes universitárias sobre conciliar trabalho e maternidade. 2018. 84 f. Dissertação (Mestrado em Saúde Coletiva) Universidade de Fortaleza, Fortaleza, 2018.

BOLZANI, Vanderlan da Silva. Mulheres na Ciência: por que ainda somos tão poucas? Ciência e Cultura, São Paulo, v. 69, n. 4, p. 56-59, 2017.

BRASIL. Lei n. 13.257, de 8 de março de 2016. Dispõe sobre as políticas públicas para a primeira infância e altera a Lei no 8.069, de 13 de julho de 1990 (Estatuto da Criança e do Adolescente), o Decreto-Lei no 3.689, de 3 de outubro de 1941 (Código de Processo Penal), a Consolidação das Leis do Trabalho (CLT), aprovada pelo Decreto-Lei $n^{\circ} 5.452$, de $1^{\circ}$ de maio de 1943 , a Lei ${ }^{\circ}$ 11.770, de 9 de setembro de 2008, e a Lei no 12.662, de 5 de junho de 2012. Diário Oficial da União, Brasília, ano CLIII, n. 46, sessão 1, p. 1-4, 9 mar. 16. Disponível em: https://www.planalto.gov.br/ccivil_03/_ato2015-2018/2016/lei/113257.htm. Acesso em: 5 jan. 2021.

BRASIL. Lei n. 13.536, de 15 de dezembro de 2017. Dispõe sobre a prorrogação dos prazos de vigência das bolsas de estudo concedidas por agências de fomento à pesquisa nos casos de maternidade e de adoção. Diário Oficial da União, Brasília, ano CLIV, n. 241, sessão 1, p. 1-2, 18 dez. 17. Disponível em: https://www.planalto.gov.br/ccivil_03/_ato2015-

2018/2017/lei/113536.htm. Acesso em: 5 jan. 2021.

EMPOWERING women in Chemistry: a global networking event. Internacional Union Of Pure And Applied Chemistry, 2019. Disponível em: https://iupac.org/event/empoweringwomen-in-chemistry-a-global-networking-event/. Acesso em: 6 jan. 2020.

FACEBOOK. Página do evento "Café da manhã com as Químicas da UFPR", 12 de fevereiro de 2019. Disponível em: https://www.facebook.com/events/607245043049018/. Acesso em: 15 jan. 2020.

FATOR F. Direção: Maria Lutterbach. Gênero e Número, 10 ed., 2018. Disponível em: http://www.generonumero.media/doc-gn-fator-f/. Acesso em: 10 jan. 2020.

GLOBAL Women's Breakfast. Internacional Union Of Pure And Applied Chemistry, c2021. Página inicial. Disponível em: https://iupac.org/gwb/2021/. Acesso em: 5 jan. 2021.

HIRATA, Helena; KERGOAT, Danièle. Novas Configurações da Divisão Sexual do Trabalho. Tradução: Fátima Murad. Cadernos de Pesquisa, São Paulo, v. 37, n. 132, p. 595-609, 2007.

IUPAC100 Global Women's Breakfast. Internacional Union Of Pure And Applied Chemistry, c2020. Página inicial. Disponível em: https://iupac.org/100/global-breakfast/. Acesso em: 6 jan. 2020.

LIMA, Betina Stefanello. O labirinto de cristal: as trajetórias das cientistas na física. Revista Estudos Feministas, Florianópolis, v. 21, n. 3, p. 883-903, 2013.

MASON, Mary Ann; GOULDEN, Marc. Do babies matter? The effect of family formation on the lifelong careers of academic men and women. University of Georgia Libraries, v. 88, n. 6, 2002. 
Entre cafés, reagentes, mulheres e empoderamento: relato sobre o "Global Women's Breakfast" em Curitiba

MATTAR, Laura Davis; DINIZ, Carmen Simone Grilo. Reproductive hierarchies: motherhood and inequalities in women's exercising of human rights. Interface - Comunic., Saude, Educ., Botucatu, v. 16, n. 40, p. 107-19, 2012.

MULHERES e meninas na ciência. Organização das Nações Unidas para a Educação, a Ciência e a Cultura, c2017a. Disponível em: http://www.unesco.org/new/pt/brasilia/naturalsciences/science-technology-and-innovation/women-and-girls-in-science/. Acesso em 6 jan. 2020.

PARENT IN SCIENCE. Parent In Science, c2018. Página inicial. Disponível em: https://www.parentinscience.com/. Acesso em: 10 jan. 2020.

SILVA, Fabiane Ferreira; RIBEIRO, Paula Regina Costa. Trajetórias de mulheres na ciência: "ser cientista" e "ser mulher". Ciênc. Educ., Bauru, v. 20, n. 2, p. 449-466, 2014.

THE NOBEL PRIZE. The Nobel Prize in Chemistry, c2021. Disponível em: https://www.nobelprize.org/prizes/chemistry/. Acesso em: 4 jan. 2020.

TOWNS, Marcy H. Coffee, Colleagues, Conversation: Empower Women and Expand Your Network through the Global Women's Breakfast, J. Chem. Educ., Washington, D.C., v. 96, n. 1, p. 1-2, 2019. Disponível em: https://pubs.acs.org/doi/pdf/10.1021/acs.jchemed.8b01029. Acesso em: 6 jan. 2020.

VELHO, Léa. Prefácio. In: SANTOS, L. W.; ICHIKAWA, E. Y.; CARGANO, D. F. (Org.). Ciência, tecnologia e gênero: desvelando o feminino na construção do conhecimento. Londrina: IAPAR, 2006. p. xiii-xviii.

VIANNA, Cláudia Pereira. O sexo e o gênero da docência. Cadernos Pagu, Campinas, n. 17/18, p. 81-103, 2001/02.

Recebido em: 15/01/2020

Aceito em: 05/04/2021 